\title{
Karoobush defoliation in the arid Karoo
}

\author{
PIÉRRE C. V. DU TOIT
}

Author is principal agricultural scientist, Pasture Science Department, Grootfontein Agricultural Development Institute, Private Bag X 529, 5900, Middelburg. Republic of South Africa.

\begin{abstract}
The relation was studied between the applied stocking rates and the degree to which sheep grazed stems of various karoobush species. A rule of thumb exists amongst farmers and research workers in the Karoo, that sheep graze stems of karoobushes with a diameter of $2 \mathrm{~mm}$ or less. This hypothesis was examined over a period of 3 years. The recently grazed off stems of Pentzia spinescens Less. (doringkaroo) and Rosenia humilis (Less.) Bremer (blou perdekaroo), the most abundant forage species, were measured by sliding Vernier callipers. Estimates of grazeable dry matter, as used in the estimate of the current grazing capacity, is based on the separation of clipped dry matter into grazeable and non-grazeable material. This separation is based on the $2 \mathrm{~mm}$ criterion. The hypothesis that sheep voluntarily graze stems with a diameter of up to $2 \mathrm{~mm}$ was rejected. The stems of less palatable species are seldom grazed at $2 \mathrm{~mm}$ diameter, while grazed stems of palatable species are often thicker than $5 \mathrm{~mm}$. It was established that sheep graze stems of the less palatable karoo bushes to a mean diameter of 1.4 to 1.6 $\mathrm{mm}$. This impacts directly on the method in which dry matter production is estimated for the purposes of determining grazing capacity. The long term grazing capacity norm for this area is $\mathbf{3 0}$ ha large stock unit ${ }^{-1}$. Based on gain ha $^{-1}$ data obtained from stocking rate trials, the grazing capacity is 33.4 ha large stock unit $^{-1}$. The stocking rate: grazed stem relation yields an optimum grazing capacity figure of $\mathbf{3 2 . 5}$ ha large stock unit ${ }^{-1}$. This indicates that monitoring the grazed stems of appropriate species can be used to set grazing capacity limits or adjust stocking rates.
\end{abstract}

Key Words: applied stocking rates, optimum stocking rates, grazed stem diameters, production.

The Ecological Index Method of grazing capacity calculation described by Vorster (1982) is commonly used in the Karoo to estimate grazing capacity from floristic composition. The contribution made by each species to the estimated grazing capacity is based on the ecological significance of the grasses and the palatability of the karoobush species. Perenniality and seral position of the grasses (climax, sub-climax or pioneer) play a role in the determination of their ecological value. The subjective rating of palatability (palatable, less-palatable and unpalatable) determine the "ecological" value of the karoobushes. Studies currently undertaken by Du Toit (1992) aim to quantify the grazing value of various plant species. For this reason a number of species, representative of pioneer to climax grasses and unpalatable to palatable karoobushes, are harvested every 3 months. The plant material is harvested in 4 reasonably homogeneous farming areas. The plants are harvested at ground level and the harvested material is separated into potentially grazeable and non-grazeable fractions, prior to further analysis.

By definition, all the material thicker than $2 \mathrm{~mm}$ is regarded as non-grazeable. This definition was applied in the studies on the chemical composition of karoobushes by Botha (1981) and Botha, et al. (1990). A field trial was undertaken in order to test this definition.

It is known that this so-called ecological value does not necessarily reflect the grazing value of a plant species or it's contribution to grazing capacity. Therefore, the use of this technique of grazing capacity estimation, leads to over- and under-estimation of the current grazing capacity.

The purpose of this paper is to :

i. Test the hypothesis that sheep select stems less than $2 \mathrm{~mm}$ in diameter for indicator species, and

ii. To determine to what degree this hypothesis can be used as an indicator of optimum stocking rates.

\section{Methods}

The trial was carried out on Biesieslaagte farm $\left(30^{\circ} 45^{\prime} \mathrm{S}, 22^{\circ}\right.$ $\left.01^{\prime} \mathrm{E}\right)$, at the Carnarvon Research Station, situated in the Arid Karoo (Acocks, 1988). Two less palatable karoobush species were selected for monitoring, they were Pentzia spinescens Less. (Gibbs Russell et al., 1987) (doringkaroo) (Smith, 1966) and Rosenia humilis (Less.) Bremer (blouperdekaroo). The less palatable species, Eriocephalus ericoides (L.f.) Druce (common kapokbush) was also considered for measurement, but was excluded, due to uneven distribution over the experimental terrain.

The species were selected in an established stocking rate trial,where Afrino sheep (a hardy sheep cross consisting of 50\% Mutton Merino, 25\% Merino and 25\% Roundribbed Afrikaner, an indigenous sheep breed) graze the range at 4 stocking rates. The trial was laid out to determine the optimum stocking rate for this area. The applied stocking rates were 26.4 ha Large Stock

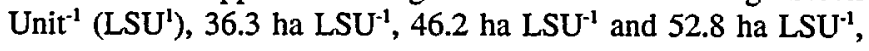


6.6 sheep were taken to represent 1 LSU, the small stock unil (SSU) in this case would be a 6 tooth Afrino wether with a mass of $50 \mathrm{~kg}$. Areas allocated to the different stocking rate treatments were $54 \mathrm{ha}, 72 \mathrm{ha}, 90 \mathrm{ha}$, and $108 \mathrm{ha}$. Each of these areas were subdivided into 3 equal sized paddocks. In each year 2 paddocks per treatment were rotationally grazed by 10 sheep, with a period of stay of 3 months. The third paddock was deferred from grazing for a full year. Due to the large area involved in the trial, $324 \mathrm{ha}$, the trial was not replicated, however, the applied stocking rates remained the same from one year to the next. Of necessity therefore, statistical treatments of the data had to be in the form of regression analyses. The gain ha ${ }^{-1}$ calculations follow Jones and Sandland (1974) and Edwards (1980). In order to tie in the stem diameter, stocking rate relation with gain ha ${ }^{-1}$ and to study the power of this relation to predict an optimum stocking rate for this area, it was decided to employ quadratic regressions of the stem data instead of linear regressions.

Three considerations support the decision to work only with the less palatable species group.

i. The less palatable species group accounts for more than $70 \%$ of the floristic composition of the range and contributes the major portion of the available forage. This group was therefore considered the most suitable to monitor.

ii. Preliminary investigations indicated that unpalatable species are seldom grazed and it is therefore unlikely that they will respond to stocking rate manipulations.

iii. It was observed that the diameter of grazed stems of the palatable species, Limeum aethiopicum Burm. (koggelmander voetkaroo) and Salsola calluna Fenzl ex C.H. Wr. (rooiganna) regularly exceeded $5 \mathrm{~mm}$, regardless of stocking rate. This can partly be ascribed to their relative palatability on the one hand and partly to their low abundance on the other. They are therefore not suitable for monitoring.

Twenty five plants per species were randomly selected in an arc, between $100 \mathrm{~m}$ and $200 \mathrm{~m}$ away from the watering point, in the most recently grazed paddock of each stocking rate. Closer to the watering point, all karoobushes are fairly severely grazed, while further away, it is more time consuming to find recently grazed stems to measure. Karoobushes that were obviously grazed quite recently, were selected for measurement. The discolouration of the wounds, left at the apex of the stems after grazing, enabled the distinction to be made between "old" grazed-off stems and recently grazed stems. Old stem wounds are greyish, while recent wounds have a strawcoloured to light-greenish tint. Stems that have a straw coloured apical stem wound, were selected for measurement and the measurement was taken at the point where the branch was browsed off. Owing to the variable palatibility of different plants of the same species, a maximum of 4 readings were taken per plant in order not to introduce bias. Recently browsed branches were selected at random on a specific plant. The readings were taken with sliding Vernier callipers. In laterally compressed stems, the mean of the widest and narrowest measurements was used, in order to provide a single measurement for that stem.

The trial period ran from the $1990 / 91$ season to the $1992 / 93$ season, with measurements being taken during February of each season. This date corresponds to the peak growth activity calculated for this area using climatic variables (Du Toit 1990). At low stocking rates fairly thin stems are grazed off. With an increase in stocking rates, thicker stems are grazed. At high stocking rates during favourable rainfall seasons, the abundance of available forage influences the thickness of the stems being grazed. The diameter of the grazed-off stems at the higher stocking rates reaches a maximum and remain constant. With these data it should be possible to calculate an optimum stocking rate from the stocking rate: grazed stem relation. It was reasoned that, with growth at its optimum and with young, succulent stems, the defoliation: stocking rate relation of the karoobushes would be described by a quadratic curve. The measured diameter of grazed stems at the different stocking rates was therefore regressed on stocking rate in a quadratic regression. This relation, in the form of the quadratic curve, can then be used to calculate the optimum stocking rate, at which the range should be grazed in this area. The asymptote of the curve represents the stocking rate at which the diameter of the grazed-off stems reaches a maximum, this stocking rate represents the optimum stocking rate.

\section{Results}

Mean diameters of grazed stems for Pentzia spp. over all seasons were 1.14 for the lightest and $1.68 \mathrm{~mm}$ for the heaviest stocking rate (Table 1). The seasonal means over all stocking rates were 1.30,1.27, and $1.54 \mathrm{~mm}$ for Pentzia spinescens. Mean diameters of grazed stems measured for Rosenia spp. over all seasons were 1.34 for the lightest and 1.89 for the heaviest stocking rate. The seasonal means over all stocking rates were $1.65,1.44$, and $1.72 \mathrm{~mm}$ for Rosenia humilis.

The fairly low mean diameter measured for Pentzia spinescens and Rosenia humilis in the high stocking rate treatment (5.5 ha $\mathrm{SSU}^{-1}$ ) during the 1992/93 season was influenced by the high proportion of Eriocephalus ericoides found in that specific camp. When present, Eriocephalus ericoides seems to be grazed in preference to Pentzia spinescens owing to the more succulent nature of it's stems.

These results coincide with the observations made by Vorster and Blom (1982), at the Grootfontein Research Station situated in the False Upper Karoo (Acocks, 1988). They found that Merino sheep on range dominated by Pentzia incana (Thunb.) Kuntze (ankerkaroo, good karoo), grazed stems to a mean diameter of $1.35 \mathrm{~mm}$, while Dorper sheep grazed stems to a mean diameter of $1.55 \mathrm{~mm}$. On this range, at the recommended stocking rates, the hypothesis that sheep voluntarily graze stems which have a diameter of up to $2 \mathrm{~mm}$, must be rejected. The stems of the less palatable species component, the most abundant species group in the Arid Karoo (Acocks, 1988), are seldom grazed below the $2 \mathrm{~mm}$ point. However, the stems of palatable species, such as Limeum spp. and Salsola spp., are frequently grazed in excess of $2 \mathrm{~mm}$ and this probably accounts for their low abundances in this range. Few measurements of the less palatable species exceeded $2 \mathrm{~mm}$. At high stocking rates, where dry matter becomes limiting, the grazing of stems exceeding $1.5 \mathrm{~mm}$ can not be regarded as being voluntary because the animals are obviously under stress. This condition is more pronounced during dry seasons (Table 1).

During the 1990/91 season, the measured diameters leveled off with an increase in stocking rate. Precipitation during 1990/91, for the 12 months preceding the month during which the measurements were taken, was $261.9 \mathrm{~mm}$ (Immelman 1993, Pers. $\mathrm{Com}^{2}$ ). This is $36 \%$ higher than the longterm median annual

Immelman, W.F. Carnarvon Research Station, P.O. Box 98, Camarvon. 7060.
Republic of South Africa. 
Table 1. Mean diameters (nm) of grazed stems at th" point of removal in the different stocking ialts, over 3 seasons.

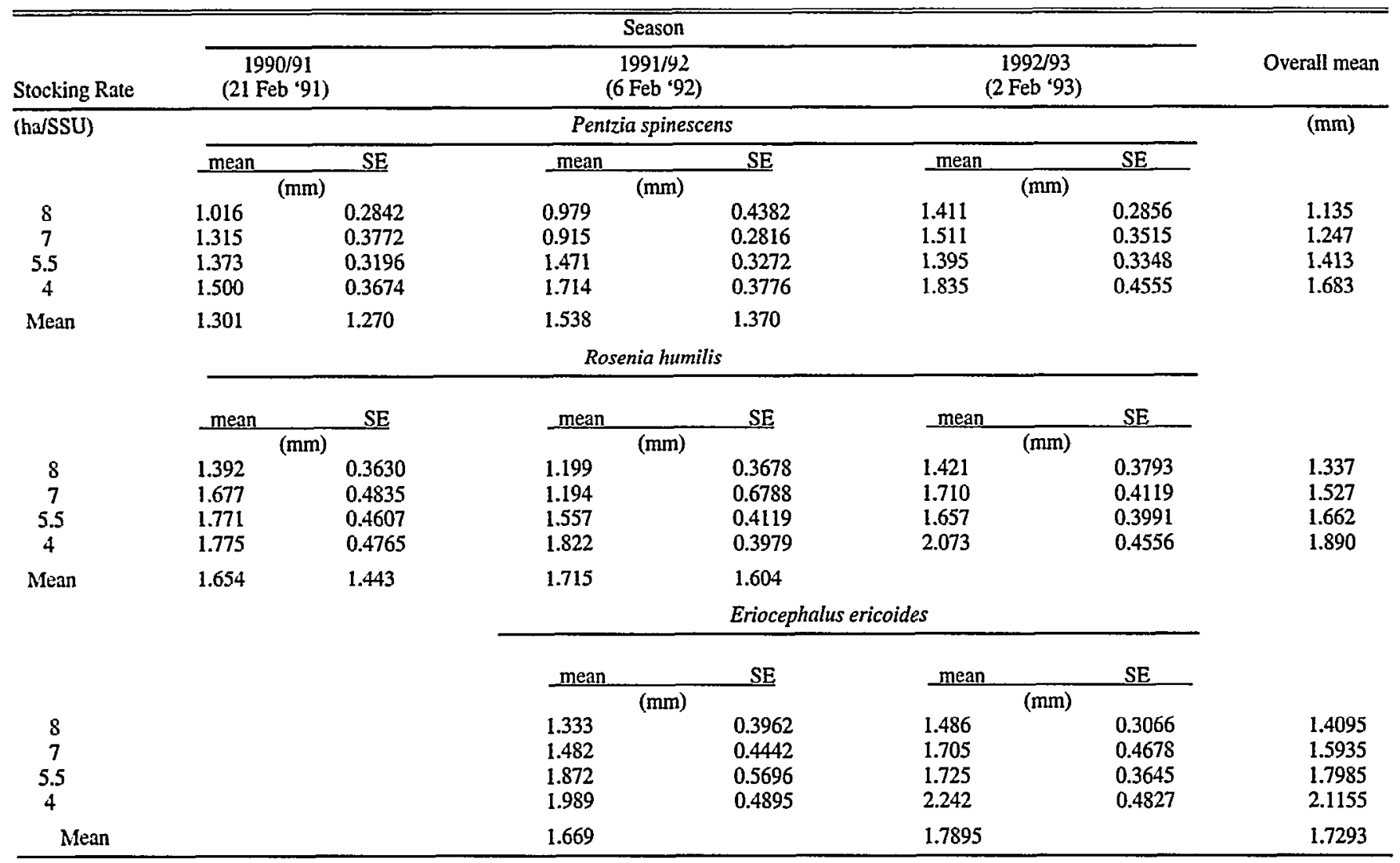

rainfall, which is $192 \mathrm{~mm}$ (Anon., 1993). An abundance of succulent forage was available. Because of the succulence of the stems, fairly thick stems were grazed, but without severe grazing being evident. The abundance of succulent forage provided sufficient forage even at high stocking rates.

During $1991 / 92$, only $50 \%(94.3 \mathrm{~mm})$ and during $1992 / 93$, only $41 \%(78.5 \mathrm{~mm})$ of the long-term median precipitation was recorded. This resulted in a slow growth rate and low dry matter accumulation.

During both the 1991/92 and 1992/93 seasons, the measured diameters increased curvi-linearly with increasing stocking rate. However, the measurements made during 1991/92 were on the whole, lower than those during 1990/91, because the material dried out from the drought and the overall stem dimensions decreased. The low mean diameters measured in the lower stocking rates, was influenced by the carry-over effect of dry matter. At the higher stocking rates, less dry matter is usually carried over to the next season and consequently the mean measured diameters increase. The mean diameters measured in the high stocking rate during 1991/92 were much higher than those during the 1990/91season.

In 1992/93 the effect of the second consecutive dry season became evident. Animals grazed very severely in order to satisfy their requirements, especially in the high stocking rate treatments, due to the low amount of dry matter carried over from the previous season and the low production during the current season. Grazed stem diameters increased sharply with increasing stocking rate (Fig. 1 and Table 1).

\section{Discussion}

Grazed Stem Diameter as an Indicator of Stocking Rate.

For the purposes of this analysis, the data obtained for Pentzia spinescens and Rosenia humilis were pooled. These species are the most abundant of the forage species on this range and belong to a group with the same palatibility rating. These species were grazed to the same degree by the animals. As can be ascertained from Table 1, the stem diameters of these 2 specics differ slightly, with the stems of Pentzia spinescens being thinner than those of Rosenia humilis. For this reason it was decided to pool the data to illustrate the influence of stocking rate on the diameter of stems grazed, as illustrated in Figure 2.

The expected stocking rate: grazed stem relation of the karoobushes is a quadratic curve. As the stocking rate increases, the grazed diameter of the stems increase but levels off at the higher stocking rates. During the favourable rainfall season of 1990/91, with growth at its optimum and with young, succulent stems available, in the low stocking rate treatment, only thin stems were grazed off $(1.01 \mathrm{~mm}$ for $P$. spinescens and $1.39 \mathrm{~mm}$ for $R$. humilis). With the increase in stocking rate thicker stems were grazed off. In the high stocking rate, the abundance of available forage influenced the thickness of the stems being grazed. There was sufficient forage available to the animals in the grazed stratum, making it unnecessary for the animals at the highest stocking rate to graze more severely in order to satisfy their requirements. The measured diameter of grazed stems decreased, from the second highest to the highest stocking rate in $P$. 


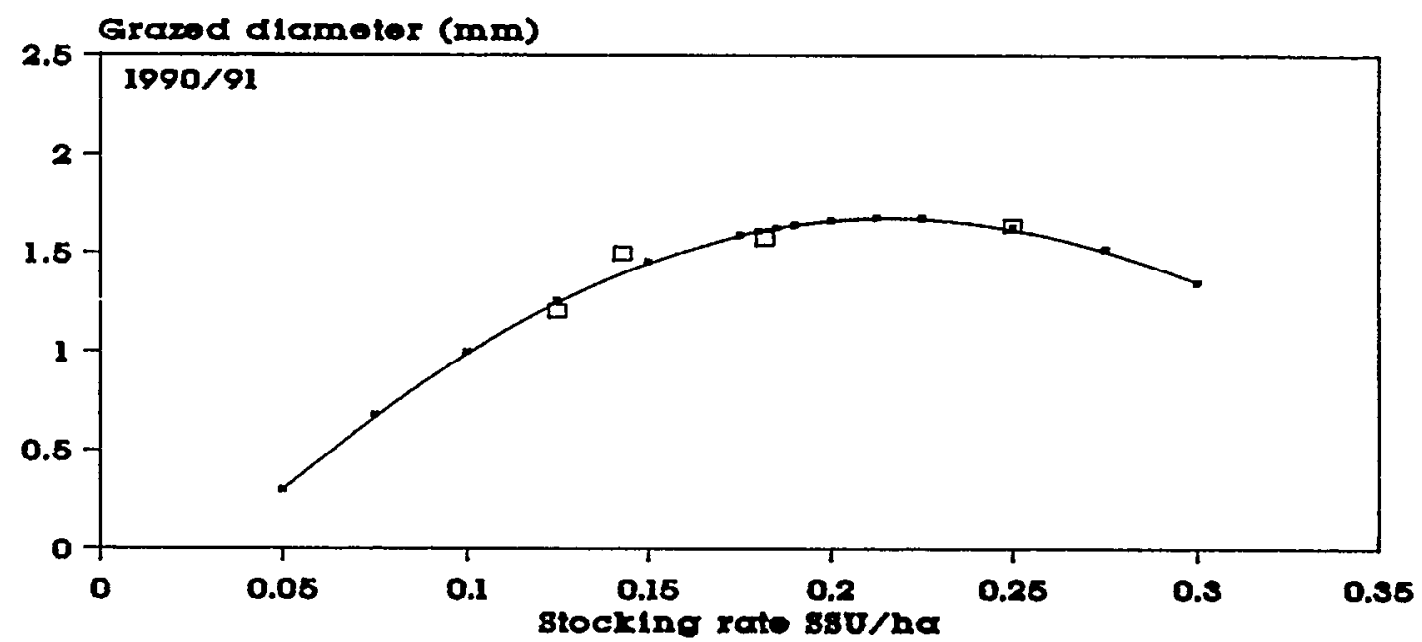

Rogression Data polnts

a

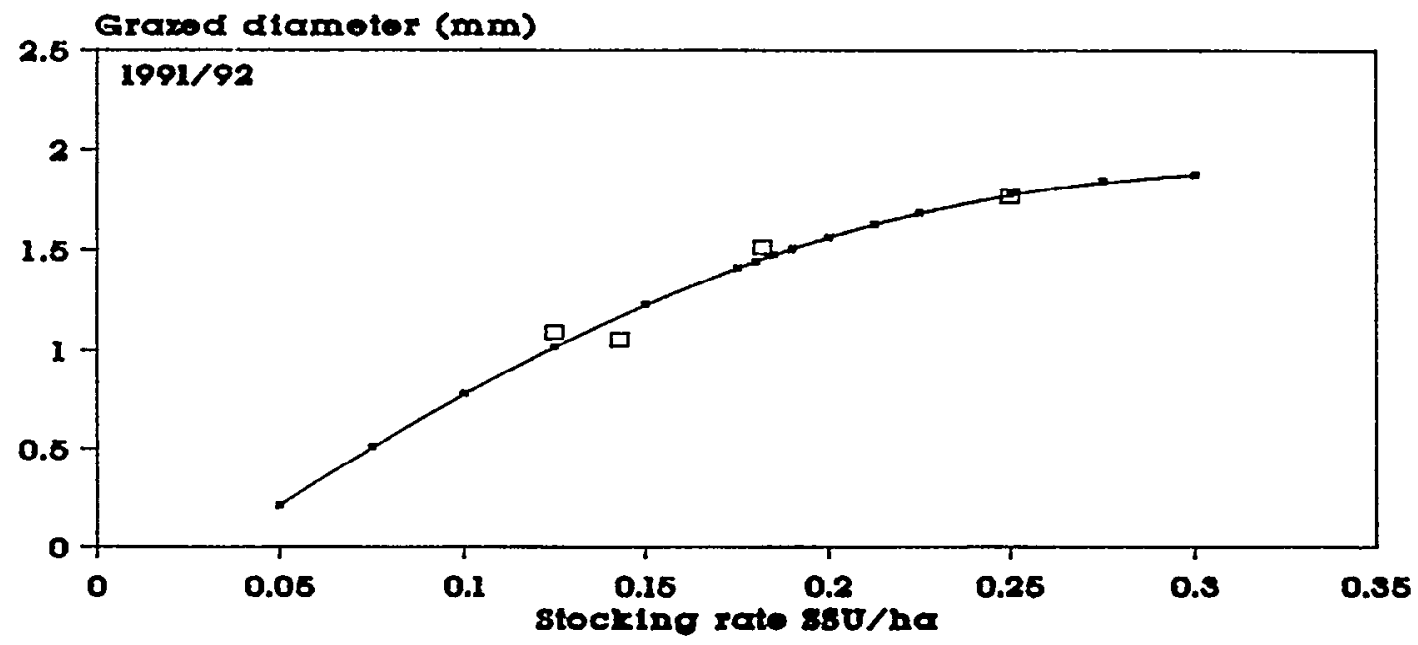

- Rogression D Data points

b

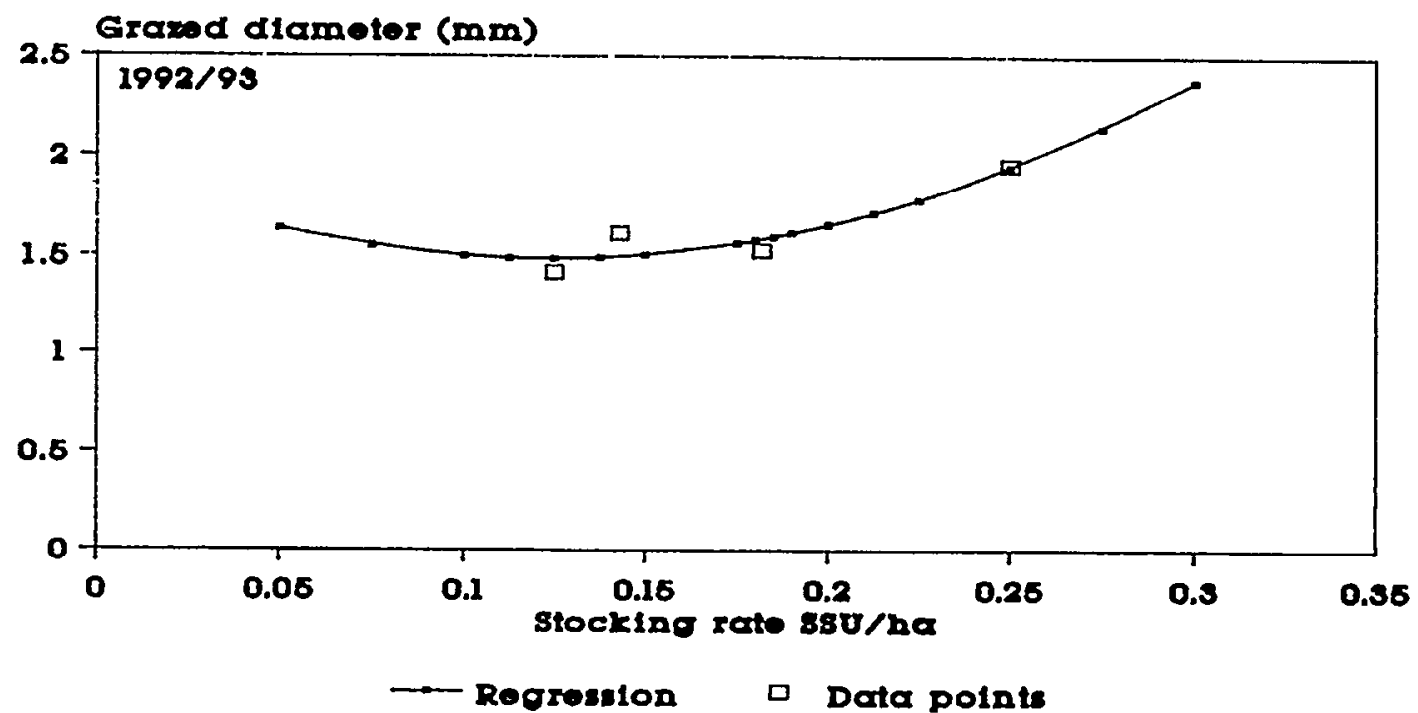

Fig. 1. Regressions of measured pooled grased stem diameters of the less palatable species, Pentzia spinescens and Rosenia humilis, over 3seasons from 1990 to 1993.
(a) $1990 / 91, Y=-0.6504+21.4 X-49.13 X^{\prime \prime}$;
(b) $1991 / 92, Y=-0.4757+14.91 X-23.58 X^{\prime \prime}$;
(c) $1992 / 93, Y=1.91-6.95 X+28.41 X^{*}$. 


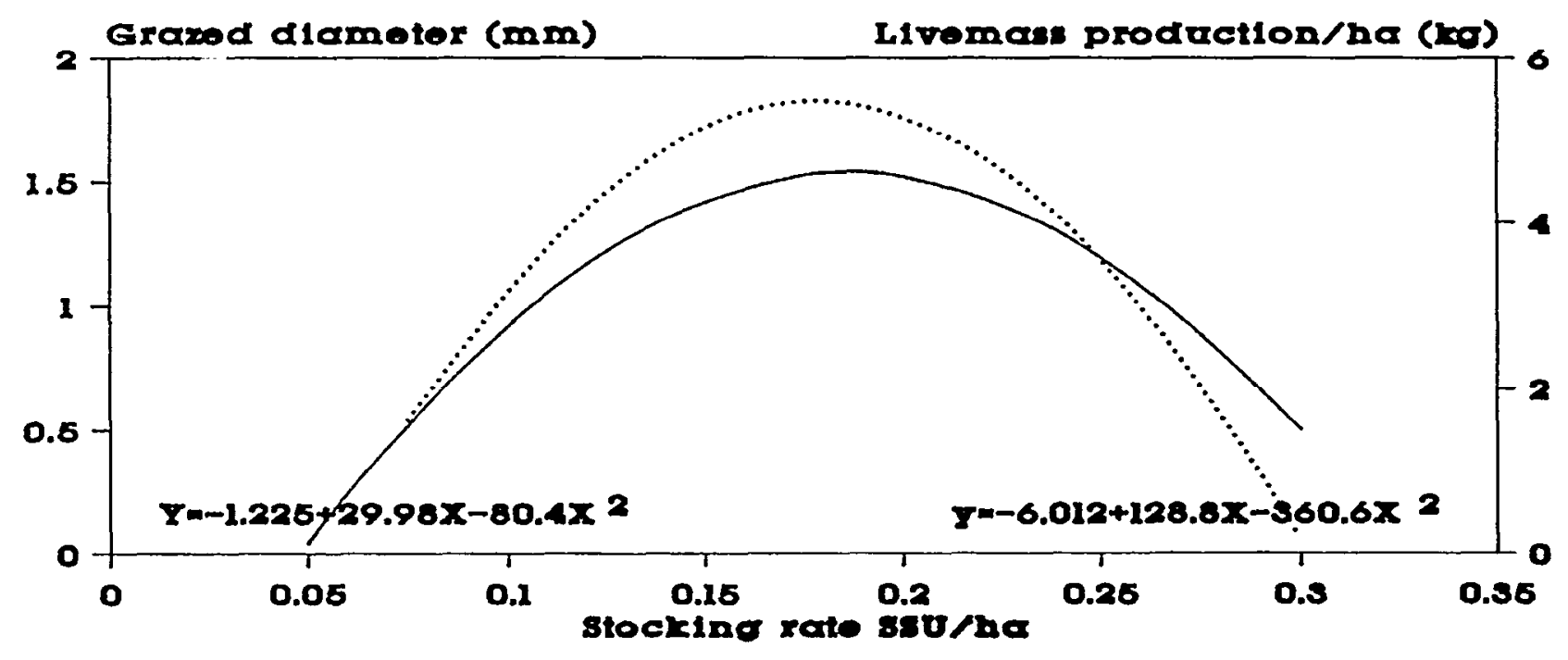

Stem diametex

Production/ma

Fig. 2. Comparisons of animal production ha $^{-1}$ and the intensity of grazing as gauged by the measurements of the mean grazed stem diameter

spinescens from $1.37 \mathrm{~mm}$ to $1.5 \mathrm{~mm}$ and in $R$. humilis from 1.77 $\mathrm{mm}$ to $1.78 \mathrm{~mm}$. This indicated that in the quadratic relation, the stems grazed off in the highest stocking rate, was already beyond the point of inflection on the curve.

The relation during the 1990/91 season was a convex parabola, in 1991/92 the relation was nearly linear and in 1992/93 the relation was a concave parabola. The shift in the slope and direction of the curve, is explained by the dry matter availability. Due to the low rainfall experienced during 1991/92 and 1992/93, dry matter production was very low. Instead of the bulk of available dry matter restricting the thickness of the stems being grazed, the animals had to graze thicker stems in order to obtain sufficient dry matter to satisfy their requirements.

As the dry seasons progress, the reserve dry matter produced during the favourable seasons becomes depleted. This is especially true for the higher stocking rate treatments. The higher diameter stems being grazed now, means that the plants are overgrazed. The bushes diminish in size and they eventually die out with continued high stocking rates being applied. It was observed that individuals of Rosenia humilis have been grazed down to such an extent in the high stocking rate treatments, that they could no longer provide sufficient forage. This leads to the less palatable species being overgrazed. Eventually the less palatable species group loses its ability to supply grazeable dry matter. Their contribution to dry matter production in the system is replaced by unpalatable species, which in this case is Eberlanzia ferox (L. Bol.) L. Bol. (doringvygie), a very fibrous plant, especially during the drought. As a result of this change in species composition, animal production declines. From this stocking rate: grazed stem relation the optimum stocking rate can be calculated.

A regression of mean grazed stem diameters on stocking rate, data of the 3 seasons were pooled for each stocking rate, yielded a quadratic curve similar to the Jones and Sandland curve (Jones and Sandland, 1974) of gain per hectare on stocking rate, recalculated from data quoted by Meyer (1992). The optimum stocking rate calculated from the animal liveweight gain per hectare : stocking rate relation is 33.36 ha large stock unit $t^{-1}$. The optimum stocking rate calculated from the grazed stem diameter:stocking rate relation, for the pooled data, is 32.46 ha large stock unit ${ }^{-1}$ (Fig. 2), while the official grazing capacity in the area, prescribed by the South African Department of Agriculture, is 30 ha large stock unit ${ }^{1}$. It is accepted that the economic optimum stocking rate is lighter (Edwards, 1981) than the optimum stocking rates calculated above. From the calculations it then follows that both the gain $\mathrm{ha}^{-1}$ and the stem diameter regressions, yield optimum stocking rates which are lighter than the officially accepted grazing capacity norm. This clearly indicates that the norm is too lenient and that it should be adjusted.

For the 1990/91 season only, the optimum stocking rate calculated from the $P$. spinescens data is 32.45 ha large stock unit ${ }^{-1}$, while in the case of $R$. humilis it is 36.62 ha large stock unit ${ }^{-1}$ (Fig. 3). It is evident that the pooled data provided a more realistic estimate of the grazing capacity, when compared to both the official grazing capacity figure and the grazing capacity figure computed from the animal liveweight gains. It is clear therefore that the grazed stem diameter is a useful parameter in the estimation of the optimum stocking rate.

\section{Estimating Stocking Rate}

The method employing stem thickness as criterion in the estimation of grazeable dry matter, often used to estimate the grazing capacity of an area, over-estimates the forage component. The consequent over-estimate of the grazing capacity, leads to over utilization. The criterion of using $2 \mathrm{~mm}$ to estimate forage may prove satisfactory where palatable to less palatable shrubs occur in a 50:50 ratio. The over-estimate of the less palatable forage component will be offset by the under-estimate of the palatable component. Where the less palatable species contribute the major portion to the forage, the mean grazed stem diameter is $1.5 \mathrm{~mm}$. This measurement is $25 \%$ lower than the previous accepted yardstick. In terms of the overall accumulated dry matter, it may be lower by as much as $50 \%$. The tremendous impact that the overestimate of the grazing capacity can have on dry matter removal is obvious. 


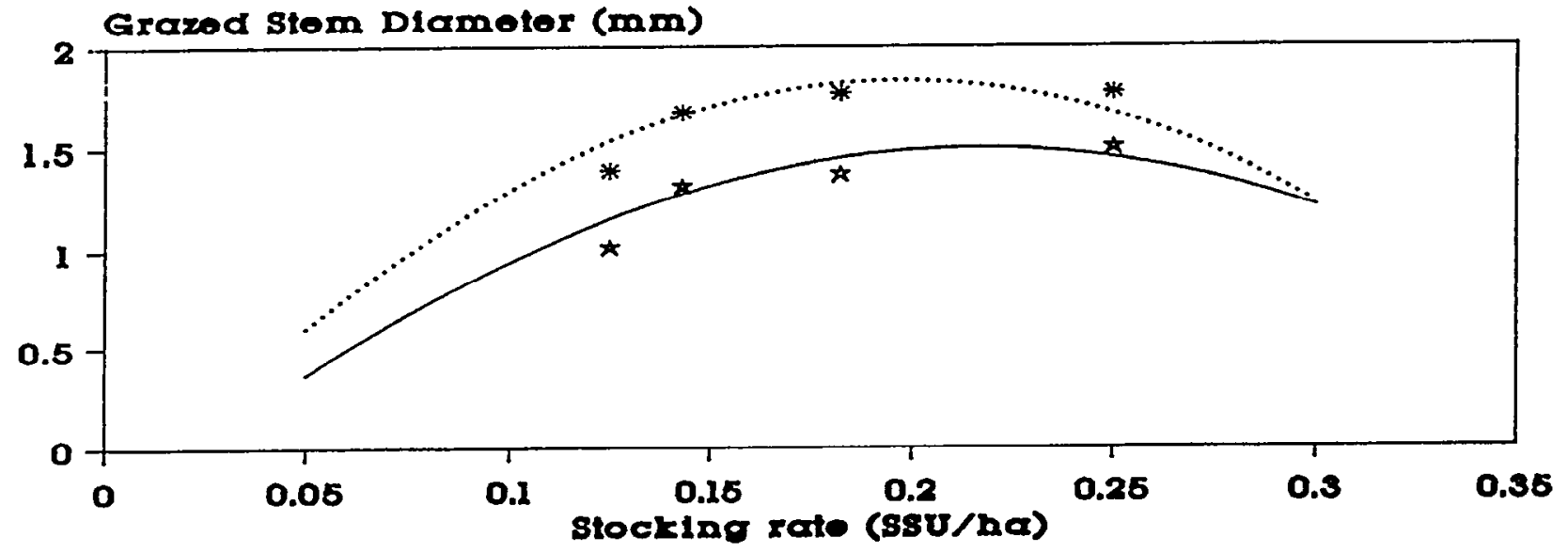

1991 season
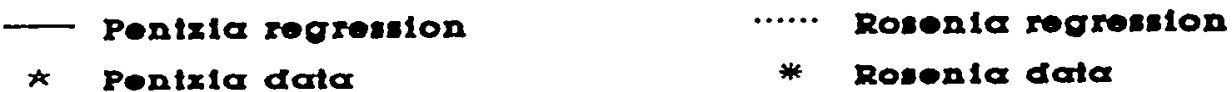

Fig. 3. The optimum stocking rates calculated for Pentzia spinescens and Rosenia humilis from the data obtained duting the first season. The regression equation for $P$. spinescens is $Y=-0.4258+17.82 \mathrm{X}-41.21 \mathrm{X}^{\prime \prime}$, with a coefficient of determination, $R^{\prime \prime}=0.96$, while the regression equation for $R$. humilis is $\mathrm{Y}=-0.3775+22.45 \mathrm{X}-56.99 \mathrm{X}^{\prime \prime}$, with a coefficient of determination, $\mathrm{R}^{\prime \prime}=0.99$

During dry periods animals graze more severely than during favourable rainfall periods in order to satisfy their dry matter requirements. Plant stems are not as succulent and tumescent as during good rainfall periods and the measured diameter of the grazed twigs decreases, as a result of the drying out of the stems. It is postulated that although the measured diameter of grazed stems decreases, the animals still graze to the same extent. When animals graze stems as thick as, or thicker during dry periods, than during good rainfall seasons, the plants are overgrazed.

In order to avoid "hidden" overgrazing, stocking rates should be lighter than the optimum stocking rate calculated from stocking rate trials, for both the animal production per hectare and the grazed stem diameter. This recommendation is especially true in the light of the over-estimation of available forage. "Hidden" overgrazing results during drought conditions when little dry matter is carried over between grazing periods and production cannot keep up with removal, because of the low dry matter accumulation. Lenient stocking rates enable animals to satisfy their dry matter requirements with a relatively low negative impact on the range, regardless of the prevailing climatic conditions. At present, the stock reduction advocated to offset the detrimental effects of the drought, benefits the range in that not all the dry matter is removed during grazing, but is carried over to be utilized during periods of low dry matter production. In the long run the hidden overgrazing results in a reduction in the vigour of the karoobushes, ultimately leading to unfavourable species composition changes, with a consequent lower grazing capacity.

\section{Conclusions}

A rule of thumb exists that sheep graze off stems of karoobushes with a diameter of $2 \mathrm{~mm}$ or less. For the purposes of grazing capacity calculation, plants are harvested at ground level and the harvested material is separated into potentially grazeable and non-grazeable fractions. By definition the material thinner than 2 $\mathrm{mm}$ is regarded as grazeable. It was established that sheep graze stems to a mean diameter of $1.4 \mathrm{~mm}$ to $1.6 \mathrm{~mm}$. The hypothesis that sheep voluntarily graze stems with a diameter of up to $2 \mathrm{~mm}$ must be rejected, on the grounds that the main source of forage, the less palatable species, are seldom grazed as thick as $2 \mathrm{~mm}$. It follows then that the method in which dry matter production is estimated for the purposes of determining grazing capacity must therefore be adjusted by some $20 \%$. Measurements of grazed stems of the less palatable category of karoobushes in the Arid Karoo, can be used to calculate optimum stocking rates. In order to avoid "hidden" overgrazing, stocking rates should be lighter than the optimum stocking rate calculated from stocking rate trials, for both the animal production $\mathrm{ha}^{-1}$ and the grazed stem diameter.

Further research is necessary in order to employ measurements of grazed stems of the less palatable karoobushes to adjust stocking rates, especially the official stocking rate norms and to monitor applied stocking rates.

\section{Literature Cited}

Acocks, J.P.H. 1988. Veld Types of South Africa. Mem. Bot. Surv. S. Afr. no. 57. Govt Printer. Pretoria.

Anon. 1993. Climate data, Institute for Soil, Climate and Water. Grootfontein Agricultural Development Institute Rep. Middelburg, C.P.

Botha, P. 1981. Die invloed van spesieseleksie deur skape, beeste en bokke op die floristiese samestelling van gemengde Karooveld. (In Afrikaans). Unpublished D.Sc. thesis. P.U. for C.H.E. Potchefstroom.

Botha, P., C.H. Erasmus, and S.C. Theron. 1990. Mean phytomass and chemical composition of a number of plant species in the Nortwestern Karoo. Technical Communication no. 227. Govt Printer, Pretoria.

Du Toit, P.C.V. 1990. Estimation of relative grazing value in dices for the different plant-ecological groups in the North-western Karoo. Grootfontein Agricultural Development Institute Report K5411/36/2/2. Middelburg, CP. 
Du Toit, P.C.V. 1992. Estimation of relative grazing value indices for the different plant-ecological groups in the Eastern Mixed Karoo. Grootfontein Agricultural Development Institute Report K5411/36/2/1. Middelburg, CP.

Edwards, P.J. 1980. The use stocking rate/animal performance models in research and extension, p. 73-77. In: D.I. Bransby (ed.), Proc. Grassl. Soc. So. Afr. 15.

Edwards, P.J. 1981. Grazing management, p. 325-334. In: N.M. Tainton (ed.), Veld and pasture management in South Africa. Gibbs Russell, G.E., W.G. Welman, E. Retief, K.L. Immelman, G.

Germishuisen, B.J. Pienaar, M. van Wyk, and A. Nicholas. 1987. List of species of southern African plants, ed 2, Recent Literature and Synonyms, part 2, Dicotyledons. Mem. Bot. Surv. So. Afr. no 56. Govt. Printer, Pretoria.
Jones. R.J. and R.L. Sandland. 1974. The relation between animal gain and stocking rate. J. Agr. Sci., Camb. 83 :335-342.

Meyer, T.C. 1992. Weikapasiteitstudies op veld in die Ariede Karoo. (In Afrikaans). Unpublished M. Sc. thesis. University of the Orange Free State. Bloemfontein.

Smith, C.A. 1966. Common names of South African plants. Mem. Bot. Surv. So. Afr. no 35. Govt Printer, Pretoria.

Vorster, M. 1982. The development of the Ecological Index Method for assessing veld condition in the Karoo, p. 84-89. In: D.I. Bransby (ed.), Proc. Grassld Soc. So. Afr. 17.

Vorster, M. and C.D. Blom. 1982. Grazing habits of Merino- and Dorper sheep on Ankerkaroo (Pentzia incana). Grootfontcin Agricultural Development Institute Rep. Middelburg, CP. 